\title{
Extension of the Chebyshev Method of Quassi- Linear Parabolic P.D.E.S With Mixed Boundary Conditions
}

\author{
Shawki A. M. Abbas*
}

Date of acceptance $3 / 3 / 2009$

\begin{abstract}
The researcher [1-10] proposed a method for computing the numerical solution to quasi-linear parabolic p.d.e.s using a Chebyshev method. The purpose of this paper is to extend the method to problems with mixed boundary conditions. An error analysis for the linear problem is given and a global element Chebyshev method is described. A comparison of various chebyshev methods is made by applying them to two-point eigenproblems. It is shown by analysis and numerical examples that the approach used to derive the generalized Chebyshev method is comparable, in terms of the accuracy obtained, with existing Chebyshev methods.
\end{abstract}

Key words: Parabolic P.D.E., quasi-Linear, chebyshev method.

\section{Introduction}

In [1-10], the authors described an algorithm based on chebyshev polynomials to compute the numerical solution to parabolic p.e.d.s of the type. $\left.\frac{\partial 2 u}{\partial x^{2}}=\sigma(u, x, t) \frac{\partial u}{\partial t}+f(u, x, t),(x, t) \in F_{1} 1\right] \times(0, T)$ ...(1.1)

Subject to

$\mathrm{u}(-1, \mathrm{t})=\mathrm{g}_{-1}(\mathrm{t}), \mathrm{u}(1, \mathrm{t})=\mathrm{g}_{1}(\mathrm{t}), \mathrm{t} \in(0, \mathrm{~T})$

And

$\mathrm{u}(\mathrm{x}, \mathrm{o})=\mathrm{K}(\mathrm{x}), \mathrm{x} \in[-1,1] \ldots(1.2)$

The purpose of this paper is to extend the method and error analysis to problems with mixed boundary conditions of the type

$$
\alpha \mathrm{u}(-1, \mathrm{t})+\beta \frac{\partial}{\partial \mathrm{x}} \mathrm{u}(-1, \mathrm{t})=\mathrm{g}_{-1}(\mathrm{t}) .
$$

And

$\gamma \mathrm{u}(1, \mathrm{t})+\delta \frac{\partial}{\partial \mathrm{x}} \mathrm{u}(\mathrm{l}, \mathrm{t})=\mathrm{g}_{1}(\mathrm{t})$.
Following the standard Chebyshev method, the $\mathrm{u}(\mathrm{x}, \mathrm{t})$ is approximated by a polynomial of degree $\mathrm{N}$ written in the form

$$
\mathrm{U}_{\mathrm{N}}(\mathrm{x}, \mathrm{t})=\sum_{\mathrm{t}=0}^{\mathrm{N}} \mathrm{a}_{\mathrm{i}}(\mathrm{t}) \mathrm{T}_{\mathrm{i}}(\mathrm{x}) \text {. }
$$

Where $T_{i}(x)$ is the Chebyshev polynomial of degree $i$, and the function

$$
\mathrm{Q}(\mathrm{x}, \mathrm{t}):=\sigma\left(\mathrm{U}_{\mathrm{N}}, \mathrm{x}, \mathrm{t}\right) \frac{\partial \mathrm{U}_{\mathrm{N}}}{\partial \mathrm{T}}+\mathrm{f}\left(\mathrm{U}_{\mathrm{N}}, \mathrm{x}, \mathrm{t}\right)
$$

Is approximated by a polynomial of degree $\mathrm{N}$ that interpolates $\mathrm{Q}(\mathrm{x}, \mathrm{t})$ at the Chebyshev points

$$
X_{N}:=\left\{x_{i}=\cos \left(\frac{i \pi}{N}\right), i=0,1, \cdot, \cdot, N\right\}
$$

We write this polynomial as

$\mathrm{Q}_{\mathrm{N}}(\mathrm{x}, \mathrm{t})=\sum_{\mathrm{i}=0}^{\mathrm{N}} \mathrm{q}_{\mathrm{i}}(\mathrm{t}) \mathrm{T}_{\mathrm{i}}(\mathrm{x}) \ldots(1.7)$

*Department of Math., College of Science, University of Baghdad, Jadiria, Baghdad, Iraq 
The coefficients $a_{i}(t)$ are then chosen so that the following equations are satisfied

$$
\begin{aligned}
& \sum_{i=0}^{N}(-1)^{i}\left(\alpha-i^{2} \beta\right) a_{i}(t)=g_{-1}(t) \\
& \text { And } \sum_{i=0}^{N}\left(\gamma+\delta i^{2}\right) a_{i}(t)=g_{1}(t) \ldots( \\
& a_{i}(t)=\sum_{s=0}^{N} A_{i, s} q_{s}(t), i=2,3, \ldots, N
\end{aligned}
$$

Where the coefficients $A_{i, s}$ are defined in Dew [1].

For sufficiently simple problems it is possible to eliminate $\mathrm{q}_{0}(\mathrm{t})$ and $\mathrm{q}_{1}(\mathrm{t})$.

When

$\mathrm{D}=\alpha(\alpha-\beta)+\alpha(\gamma+\delta) \neq 0$

It is then possible to use an obvious extension of the method described in Dew [1]

Alternatively we can consider (1.8) as a system of algebraic and ordinary differential equations and compute the numerical solution directly using an o.d.e.solver adapted to solve equations of the form $\phi\left(\mathrm{t}, \mathrm{y}, \mathrm{y}^{\prime}\right)=0$ (in standard notation).

Gear's method, for example, can readily be implemented in this form. Equations (1.8) can conveniently be mapped into the solution values at the Chebyshev points by using the mapping matrix $\Omega$ whose (i,j)th element is defined as

$\Omega_{\mathrm{i}, \mathrm{j}}:=\mathrm{T}_{\mathrm{i}}\left(\mathrm{x}_{\mathrm{j}}\right), \mathrm{x}_{\mathrm{j}} \in \mathrm{X}_{\mathrm{N}} \ldots$

The inverse of $\Omega$ can be determined analytically and is therefore more satisfactory than the mapping matrix proposed in Dew [1]. Implementing (1.8) in this form has the advantage that the problem specifications can be generalized.
(For example, the method can be extended to boundary conditions of the form.

$\hat{\mathrm{g}}_{\mathrm{i}}\left(\mathrm{u}(-1, \mathrm{t}), \mathrm{u}(\mathrm{l}, \mathrm{t}) \frac{\partial \mathrm{u}(-1, \mathrm{t})}{\partial \mathrm{x}}, \frac{\partial \mathrm{u}(\mathrm{l}, \mathrm{t})}{\partial \mathrm{x}}, \mathrm{t}\right)=0$

$\mathrm{i}=1,2$

Numerical experiments indicate however that it is more satisfactory to solve, where possible, an explicit system of ordinary differential equations. In the next section we shall consider a new algorithm which reduces the differential equations to an explicit system of ordinary differential equations when there are derivative boundary conditions. An error analysis for the linear problem shows that the new algorithm is likely to lead, for sufficiently large $\mathrm{N}$, to a more accurate solution than the solution obtained using (1.8).

The algorithm is then extended to a global element method which can be used when the solution $\mathrm{u}(\mathrm{x}, \mathrm{t})$ cannot be adequately represented by a polynomial defined on $[-1,1]$ for each $\mathrm{t} \in(0 . \mathrm{T})$.

\section{An Improved Algorithm}

Define

$\mathrm{R}(\mathrm{u}, \mathrm{x}, \mathrm{t}):=\sigma(\mathrm{u}, \mathrm{x}, \mathrm{t}) \frac{\partial \mathrm{u}}{\partial \mathrm{t}}+\mathrm{f}(\mathrm{u}, \mathrm{x}, \mathrm{t})$.

Then an improved algorithm can be derived by noting that the derivative $\partial \mathrm{u} / \partial \mathrm{x}$ can be estimated from the formula [8].

$$
\frac{\partial u}{\partial x}=\int^{x} R(u, x, t) d x+A
$$

\section{Where}

$\mathrm{A}=1 / 2(\mathrm{u}(1, \mathrm{t})-\mathrm{u}(-1, \mathrm{t})-(\mathrm{H}(1, \mathrm{t})-\mathrm{H}(-$ $1, \mathrm{t})))$

And 
$H(x, t)=\iint^{x} R(u, x, t) d x d x$

The integral appearing in the above expression are indefinite integrals. The solution $\mathrm{u}(\mathrm{x}, \mathrm{t})$ is again approximated by a polynomial for degree $\mathrm{N}$ written as

$$
\mathrm{U}_{\mathrm{N}}^{\mathrm{T}}(\mathrm{x}, \mathrm{t})=\sum_{\mathrm{i}=0}^{\mathrm{N}} \mathrm{a}_{\mathrm{i}}^{\mathrm{T}}(\mathrm{t}) \mathrm{T}_{\mathrm{i}}(\mathrm{x}) \ldots
$$

And

$\overline{\mathrm{Q}}(\mathrm{x}, \mathrm{t}):=\mathrm{R}\left(\mathrm{U}_{\mathrm{N}}^{\mathrm{T}}, \mathrm{x}, \mathrm{t}\right) \ldots$

The coefficients $\left\{\mathrm{a}^{\mathrm{T}}{ }_{\mathrm{i}}(\mathrm{t})\right\}$ are chosen so that they satisfy the equations

$a_{i}^{T}(t)=\sum_{s=0}^{N} A_{i, s} \overline{q_{s}}, i=2,3, \ldots, N$

$\sum_{i=0}^{N}\left(\begin{array}{l}(-1)^{i} \alpha+\frac{1}{2} \beta\left(1-(-1)^{i}\right) a_{i}^{T}(t)+ \\ \beta\left(e_{i}^{(-1)}-E_{I}\right) \overline{q_{i}}(t)=z^{(-1)}\end{array}\right)$

$\left.\sum_{i=0}^{N}\left(\begin{array}{l}\partial+\frac{1}{2} \delta\left(1-(-1)^{i}\right) a_{i}^{T}(t)+\partial\left(e_{i}^{(1)}-E_{i}\right) \\ \bar{q}_{i}(t)=z^{(1)}\end{array}\right)\right\}$

...(2.7)

Where the coefficients $\left\{\mathrm{q}_{\mathrm{i}}\right\}$ are the Chebyshev coefficients for $\bar{Q}(\mathrm{x}, \mathrm{t})$ interpolated at the Chebyshev points, $x_{i}$ $\in \mathrm{X}_{\mathrm{N}}$, and

$e_{i}^{(y)}=\left[\int^{x} T_{i}(x) d x\right]_{x=y}$,

$E_{i}=\frac{1}{2}\left(1-(-1)^{i}\right)\left[\iint^{x} T_{i}(x) d x\right]_{x=1}$

The parameter $\mathrm{Z}$ is defined as

$z^{(y)}=\sum_{S=N-1}^{N} A_{s+2, s} \overline{q_{s}}(t) z_{s}^{(y)}+g_{y}(t), y= \pm 1$

Where $\mathrm{Zs}_{\mathrm{s}}^{(\mathrm{y})}$ is given in sections3.

The coefficients $\left\{\mathrm{a}^{\mathrm{T}}{ }_{\mathrm{i}}, \overline{\mathrm{q}}_{\mathrm{i}}\right\}$ can then be mapped into the solution values evaluated at the Chebyshev points using the mapping matrix $\Omega$ defined by Eq. (1.10). Equations (2.7) define a system of first order o.d.e.s when $\beta$ and/or $\delta \neq 0$, which can be written (if desired) in normal form.

A feature of Chebyshev method is that it is easy to obtain the perturbed form of the differential equation that $\mathrm{U}_{\mathrm{N}}(\mathrm{x}, \mathrm{t})$ exactly satisfies. A similar result can be shown for the improved algorithm. Define the perturbation function as

$P_{N}(x, t):=\sum_{S=N+1}^{N+2} \bar{q}_{s-2} A_{S, S-2} T_{S}(t)$.

By choosing $Z^{(-1)}(t)=\beta \phi(-1, t)$ and

$Z^{(1)}(t)=\delta \phi(1, t) \ldots(2.11)$

It is easly seen that $\mathrm{U}_{\mathrm{N}}^{\mathrm{T}}(\mathrm{x}, \mathrm{t}) \equiv \mathrm{U}_{\mathrm{N}}$ $(\mathrm{x}, \mathrm{t}),[2]$.

3. An Error Analysis For The Linear Boundary Value Problem:

The nature of the approximation can most clearly be seen by considering the differential equation

$\frac{\partial 2 \mathrm{u}}{\partial \mathrm{x}^{2}}=\mathrm{f}(\mathrm{x}, \mathrm{t})$

$\mathrm{x} \in[-1,1]$ for each $\mathrm{t} \in(0, \mathrm{~T}] \ldots(3.1)$

Subject to the boundary conditions (1.4). In this case

$\mathrm{Q}(\mathrm{x}, \mathrm{t})=\overline{\mathrm{Q}}(\mathrm{x}, \mathrm{t})=\mathrm{f}(\mathrm{x}, \mathrm{t})=\sum_{\mathrm{i}=0}^{\infty} \mathrm{fi}(\mathrm{t}) \mathrm{T}_{\mathrm{i}}(\mathrm{x})$

And

$\mathrm{Q}(\mathrm{x}, \mathrm{t})=\overline{\mathrm{Q}}_{\mathrm{n}}(\mathrm{x}, \mathrm{t})=\mathrm{f}_{\mathrm{N}}(\mathrm{x}, \mathrm{t})=\sum_{\mathrm{i}=0}^{\mathrm{N}} \mathrm{f}_{\mathrm{i}}^{(\mathrm{N})}(\mathrm{t}) \mathrm{T}_{\mathrm{i}}(\mathrm{x})$

Define

$\mathrm{P}_{\mathrm{q}}(\mathrm{x}, \mathrm{t})=\sum_{\mathrm{S}=\mathrm{N}+1}^{\mathrm{N}+2} \mathrm{~A}_{\mathrm{S} . \mathrm{S}-2} \mathrm{q}_{\mathrm{S}-2}\left\{\mathrm{~T}_{\mathrm{S}}(\mathrm{x})-\mathrm{L}_{1, \mathrm{~s}} \mathrm{x}-\mathrm{L}_{0, \mathrm{~s}}\right\}$

... (3.2)

Where the coefficients $\mathrm{L}_{1, \mathrm{~s}}$ and $\mathrm{L}_{0 . \mathrm{s}}$ are given by 
$\left[\begin{array}{ll}\alpha & \beta-\alpha \\ \gamma & \delta+\gamma\end{array}\right]\left[\begin{array}{l}1_{0, s} \\ 1_{1, s}\end{array}\right]=\left[\begin{array}{ll}\left(\alpha-\beta s^{2}\right) & (-1)^{s} \\ \gamma-\delta s^{2}\end{array}\right]$

And

$\overline{\mathrm{P}}_{\mathrm{q}}(\mathrm{x}, \mathrm{t})=\sum_{\mathrm{S}=\mathrm{N}+1}^{\mathrm{N}+2} \mathrm{~A}_{\mathrm{S}, \mathrm{S}-2} \mathrm{q}_{\mathrm{S}-2}\left\{\mathrm{~T}_{\mathrm{S}}(\mathrm{x})-\mathrm{L}_{1, \mathrm{~s}} \mathrm{x}-\mathrm{L}_{0, \mathrm{~s}}\right\}$

Where the coefficients $\mathrm{L}_{1, \mathrm{~S}}$ and $\mathrm{L}_{0, \mathrm{~S}}$ are given by

$$
\begin{aligned}
& {\left[\begin{array}{ll}
\alpha & \beta-\alpha \\
\gamma & \delta+\bar{\gamma}
\end{array}\right]\left[\begin{array}{l}
\mathrm{L}_{0, \mathrm{~s}} \\
\mathrm{~L}_{1, \mathrm{~s}}
\end{array}\right]} \\
& =\left[\begin{array}{l}
-\alpha(-1)^{\mathrm{S}}+\beta \frac{\left(1-(-1)^{\mathrm{S}}\right)}{2}+Z_{\mathrm{S}}^{(-1)} \\
-\gamma+\delta \frac{\left(1-(-1)^{\mathrm{S}}\right)}{2}+Z_{\mathrm{S}}^{(1)}
\end{array}\right]
\end{aligned}
$$

The parameter $\mathrm{Zs}^{( \pm 1)}$ can be chosen as

$Z_{\mathrm{S}}^{(-1)}=\alpha(-1)^{\mathrm{S}}-\beta \frac{\left(1-(-1)^{\mathrm{S}}\right)}{2}$

And

$Z_{\mathrm{S}}^{(-1)}=\gamma-\delta \frac{\left(1-(-1)^{\mathrm{S}}\right)}{2}$

Providing that $\beta$ and/or $\delta$ are non zero. If $\beta=\delta=0$ then it is necessary to ensure that the boundary conditions are exactly satisfied and hence

$Z^{(1)}{ }_{s}=Z^{(-1)}{ }_{s}=0$

The main advantage of introducing $Z_{\mathrm{s}}^{( \pm 1)}$ is that it simplifies the expression for the perturbation term which makes it easier to compute error estimates.

\section{Global Element Chebyshev Method}

For a number of parabolic p.d.e.s arising in practice it is not sufficient to approximate the solution by a polynomial defined on the interval [$1,1]$ for each $t$. In such cases a global element Chebyshev method can be used. That is we partition the interval [$1,1]$ into elements $\left\{\mathrm{I}_{\mathrm{m}}:=\left[\mathrm{y}_{\mathrm{m}}, \mathrm{y}_{\mathrm{m}+1}\right], \mathrm{m}=\right.$ $\left.1,2, \ldots, \mathrm{M}, \mathrm{y}_{1}=-1, \mathrm{y}_{\mathrm{m}}=1, \mathrm{y}_{\mathrm{m}}<\mathrm{y}_{\mathrm{m}+1}\right\}$ and write the solution as

$$
u(x, t)=\bigcup_{m=1}^{M} u^{m}(x, t) \text {. }
$$

$\mathrm{u}(\mathrm{x}, \mathrm{t})$ is the computed solution at the point $(x, t)$, where

$\mathrm{u}^{\mathrm{m}} \quad(\mathrm{x}, \mathrm{t}):=\mathrm{u}(\mathrm{x}, \mathrm{t}), \quad \mathrm{x} \in \mathrm{I}_{\mathrm{m}}$ and zero elsewhere.

Define $\quad \mathrm{W}_{\mathrm{m}}: \quad \mathrm{I}_{\mathrm{m}} \rightarrow[-1,1] \quad$ and approximate the solution by

$$
\mathrm{U}_{\mathrm{N}}^{\mathrm{G}}(\mathrm{x}, \mathrm{t})=\bigcup_{\mathrm{m}=1}^{\mathrm{M}}(\mathrm{x}, \mathrm{t})
$$

Where

$$
\mathrm{U}_{\mathrm{N}}^{\mathrm{m}}(\mathrm{x}, \mathrm{t})=\sum_{\mathrm{i}=0}^{\mathrm{N}_{\mathrm{m}}} \mathrm{a}_{\mathrm{m}, \mathrm{i}} \mathrm{T}_{\mathrm{i}}\left(\mathrm{W}_{\mathrm{m}}(\mathrm{x})\right), \mathrm{x} \in \mathrm{I}_{\mathrm{m}},=0
$$

elsewhere.

At the internal nodes we impose the boundary conditions

$$
\left.\mathrm{U}_{\mathrm{N}}^{\mathrm{m}}\left(\mathrm{x}_{\mathrm{m}}, \mathrm{t}\right)=\mathrm{U}_{\mathrm{N}}^{\mathrm{m}+1}\left(\mathrm{x}_{\mathrm{m}}, \mathrm{t}\right)\right\} \mathrm{m}=2,3, \ldots, \mathrm{M}
$$

And

$\left.\frac{\partial \mathrm{U}_{\mathrm{N}}^{\mathrm{m}}}{\partial \mathrm{x}}\left(\mathrm{x}_{\mathrm{m}}, \mathrm{t}\right)=\frac{\partial \mathrm{U}_{\mathrm{N}}^{\mathrm{m}+1}}{\partial \mathrm{x}}\left(\mathrm{x}_{\mathrm{m}}, \mathrm{t}\right)\right\} \mathrm{m}=2,3, \ldots, \mathrm{M}$

We assume that the function $\mathrm{R}$ (defined in Eq. (2.1)) is continuous function in its arguments $\mathrm{u}$ and $\mathrm{t}$ for all $\mathrm{t} \in(0, \mathrm{~T}]$ and $\mathrm{u} \in \mathrm{F}$ and that it is a piecewise continuous function for the $\mathrm{x}$ variable, $x \in[-1,1]$. Any discontinuities in $\mathrm{R}$ must be at the internal nodes. We further assume that

$Q^{G}(x, t)=R\left(U_{N}^{G}, x, t\right)$

Can be adequately represented by a piecewise polynomial

$\mathrm{Q}_{\mathrm{N}}^{\mathrm{m}}(\mathrm{x}, \mathrm{t})=\bigcup_{\mathrm{m}=1}^{\mathrm{M}} \mathrm{Q}_{\mathrm{N}}^{\mathrm{m}}(\mathrm{x}, \mathrm{t})$

Where 
$\mathrm{Q}_{\mathrm{N}}^{\mathrm{m}}(\mathrm{x}, \mathrm{t})=\sum_{\mathrm{i}=0}^{\mathrm{N}_{\mathrm{m}}} \mathrm{q}_{\mathrm{m}, \mathrm{i}} \mathrm{T}_{\mathrm{i}}\left(\mathrm{W}_{\mathrm{m}}(\mathrm{x})\right), \mathrm{x} \in \mathrm{I}_{\mathrm{m}},=0$

elsewhere

Where $Q_{N}^{m}(x, t)$ interpolates $Q_{N}^{G}(x, t)$ at the points

$\overline{\mathrm{x}}_{\mathrm{m}}:=\left\{\mathrm{W}_{\mathrm{m}}\left(\mathrm{x}_{\mathrm{i}}\right), \mathrm{x}_{\mathrm{i}} \in \mathrm{x}_{\mathrm{Nm}}\right\}$

The algorithm given in section 2 can then be extended. That is the coefficients $\left\{\mathrm{a}_{\mathrm{m} . \mathrm{i}}\right\}$ are chosen to satisfy the equations.

$$
\begin{aligned}
& \mathrm{a}_{\mathrm{m}, \mathrm{i}}=\mu_{\mathrm{m}}^{2} \sum_{\mathrm{S}=0}^{\mathrm{N}_{\mathrm{m}}} \mathrm{A}_{\mathrm{i}, \mathrm{s}} \mathrm{q}_{\mathrm{m}, \mathrm{s}}, \mathrm{m}=1,2, \ldots, \mathrm{M} \\
& \mathrm{i}=2, \ldots, \mathrm{N}_{\mathrm{m}} \\
& \sum_{\mathrm{i}=0}^{\mathrm{N}_{1}}\left(\alpha+\frac{1}{2} \beta\left(\mathrm{l}-(-1)^{\mathrm{i}}\right) \mathrm{a}_{1, \mathrm{i}}+\mu_{1} \beta(\mathrm{t})\right. \\
& \sum_{\mathrm{i}=0}^{\mathrm{N}_{\mathrm{M}}}\left(\gamma+\frac{1}{2} \gamma\left(1-(-1)-\mathrm{E}_{\mathrm{i}}\right) \mathrm{q}_{1, \mathrm{i}}\right) \\
& (\mathrm{t})
\end{aligned}
$$

Together with the condition for continuity of the derivative at the internal node.

$$
\sum_{\mathrm{i}=0}^{\mathrm{N}_{\mathrm{m}}} \frac{1}{2}\left(1-(-1)^{\mathrm{i}}\right) \mathrm{a}_{\mathrm{m}, \mathrm{i}}+\mu_{\mathrm{m}}\left(\mathrm{e}_{\mathrm{i}}^{(-1)}-\mathrm{E}_{\mathrm{i}}\right) \mathrm{q}_{\mathrm{m}, \mathrm{i}}
$$

$-\sum_{\mathrm{i}=0}^{\mathrm{N}_{\mathrm{m}+1}} \frac{1}{2}\left(1-(-1)^{\mathrm{i}}\right) \mathrm{a}_{\mathrm{m}+1, \mathrm{i}}+\mu_{\mathrm{m}+1}\left(\mathrm{e}_{\mathrm{i}}^{(1)}-\mathrm{E}_{\mathrm{i}}\right) \mathrm{h}_{\mathrm{m}+1}=0$

$\mathrm{m}=2,3, \ldots, \mathrm{M}$

Where

$\mu_{\mathrm{m}}=\left(\mathrm{y}_{\mathrm{m}+1}-\mathrm{y}_{\mathrm{m}}\right) / 2$

The coefficients $\left\{\mathrm{a}_{\mathrm{m} . \mathrm{i}}, \mathrm{q}_{\mathrm{m} . \mathrm{i}}\right\}$ can be mapped into the solution values at the points $\bar{X}_{\mathrm{m}}$ using the mapping matrix $\Omega$ (1.11) defined on each element such that the continuity of $\mathrm{U}_{\mathrm{N}}{ }^{\mathrm{G}}(\mathrm{x}, \mathrm{t})$ and $Q^{G}(x, t)$ is preserved at the internal nodes.
The algorithm requires a slight modification in the case when $\mathrm{R}$ is only piecewise continuous at the internal nodes.

If $\beta$ and/or $\delta \neq 0$ then the above equations mapped into the solution values defines a system of ordinary differential equations which can be solved by Gear's method. The Jacobian matrix arising in Gear's method is banded with a maximum bandwidth of $\max _{\mathrm{m}}\left(\mathrm{N}_{\mathrm{m}}+\mathrm{N}_{\mathrm{m}+1}+1\right)$. In the case when $\beta=\delta=0$ the same equations can be reduced to a system of ordinary differential equations and two algebraic equations

It is easily shown that the function $\mathrm{U}_{\mathrm{N}}^{\mathrm{G}}(\mathrm{x}, \mathrm{t})$ satisfies a perturbed form of the original differential equation. The error analysis given in this paper and the techniques for estimating the error described in [3-6] can be extended to the global element method. In particular it is possible to estimate the error in the solution across each element.

\section{Comparison with Existing} Chebyshev Methods

In this section we compare the approach used to derive the generalized Chebyshev Method with existing Chebyshev methods.

For the non-polar problem, $\mathrm{m}=0$, with $\phi=1$ we compare the method with the Berzins and Dew (1980) method. The main difference is that the Berzins and Dew method we apply prior integration twice (see Fox and Parker (1968)) to obtain an extension of the Knibb and Scraton (1971) method.

Whereas in the present algorithm we apply prior integration once and obtain the derivative of the solution directly from the Chebyshev series expansion of the solution. 
We can easily modify the generalized Chebyshev method so that if is equivalent to the Berzins and Dew (1980) method by perturbing the relationship between the Chebyshev coefficients of $u$ and $\partial u / \partial x$. That is we replace in equation: the coefficients $\mathrm{a}_{\mathrm{j}, \mathrm{i}}$ and $\mathrm{a}_{\mathrm{j}, \mathrm{i}}{ }^{(1)}, \mathrm{a}_{\mathrm{j}}{ }^{(1)}{ }_{\mathrm{Nj}}=0, \mathrm{a}_{\mathrm{j}}{ }^{(1)}{ }_{\mathrm{Nj}-1}=2 \mathrm{~N}_{\mathrm{i}} \mathrm{a}_{\mathrm{j}}$, $\mathrm{N} / \mathrm{Mj}$.

$a_{j, i}^{(1)}=\frac{1}{\mu_{j}}\left\{2(i+1) a_{j, i+1}\right\}+a_{j, 1+2}^{(1)}$

$\mathrm{i}=\mathrm{N}_{\mathrm{j}-2}, \mathrm{~N}_{\mathrm{j}-3}, \ldots, 0$

$a_{j}, N_{j}$ by $a_{j}, N_{j}-q_{j}, N /\left[4\left(N_{j+1}\right) N_{j}\right]$

And

$a_{j}, N_{j-1}$ by $\left.a_{j}, N_{j-1}-q_{j}, N_{j-1} /\left[4 N_{j}\left(N_{j-1}\right)\right]\right]$ ...(5.1)

The simple Eigenvalue Problem

To illustrate the effect of applying prior integration once or twice we consider the simple eigenvalue problem

$\frac{\mathrm{d} 2 \mathrm{v}}{\mathrm{dx}^{2}}+\lambda \mathrm{v}=0, \mathrm{x} \in[0,1]$

Subject to

$\alpha v+\beta \frac{d v}{d x}=0$ at $x=0$

And

$\gamma \mathrm{v}+\partial \frac{\mathrm{dv}}{\mathrm{dx}=0}$ at $\mathrm{x}=1$

Where

$\alpha(\gamma+\delta)-\gamma(\beta-\alpha) \neq 0\}$

We approximate $\mathrm{v}(\mathrm{x})$ by a polynomial of degree $\mathrm{N}$, written as:

$\mathrm{V}_{\mathrm{N}}(\mathrm{x})=\sum_{\mathrm{i}=0}^{\mathrm{N}} \mathrm{a}_{\mathrm{i}} \mathrm{T}_{\mathrm{i}}(2 \mathrm{x}-1), \mathrm{x} \in[0,1]$,

And obtain an estimate of the eigenvalues of (5.2) from the eigenvalues of the generalized matrix eigenvalue problem
$\mathrm{Aa}+\lambda * \mathrm{~B}_{\mathrm{a}}=0$

Where

$\mathbf{A}=\left[\mathrm{a}_{0}, \mathrm{a}_{1}, \ldots, \mathrm{a}_{\mathrm{n}}\right]^{\mathrm{T}}$

The $(\mathrm{N}+1) \times(\mathrm{N}+1)$ matrices $\mathrm{A}$ and $\mathrm{B}$ are formed using prior integration either once or twice and by adding two extra equations which arise from the boundary conditions.

We have two alternatives, either

a) We make $V_{N}$ exactly satiety the boundary conditions, e.g.

$$
\alpha \sum_{\mathrm{i}=0}^{\mathrm{N}} \mathrm{a}_{\mathrm{i}}(-1)^{\mathrm{i}}-\beta \sum_{\mathrm{i}=0}^{\mathrm{N}} \mathrm{i}^{2}(-1)^{\mathrm{i}} \mathrm{a}_{\mathrm{i}}=0
$$

As suggested in Kinbb and Scraton (1971) or

b) We can use an approximate formula for the derivative of $V_{N}$. So that $V_{N}$ satisfies a perturbed form of the boundary conditions, as suggested in Berzins and Dew and used in this paper.

\section{Numerical Example}

To compare the relative accuracy of the solution $U_{N}(x, t)$ and $U_{N}^{T}(x, t)$ whose coeff-icients $\left\{\mathrm{a}_{\mathrm{i}}\right\}$ satisfy Eqs. (1.8) and (2.7) respectively we have considered the parabolic p.d.e

$\frac{\partial \mathrm{u}}{\partial \mathrm{t}}=\frac{\partial 2 \mathrm{u}}{\partial \mathrm{x}^{2}}+\mathrm{x}^{2} \mathrm{e}^{-\mathrm{u}},(\mathrm{x}, \mathrm{t}) \in[0,1] \mathrm{x}(0,8]$

Subject to

$\frac{\partial \mathrm{u}(0, \mathrm{t})}{\partial \mathrm{x}}=0, \mathrm{t} \in(0,8]$,

$\mathrm{u}(\mathrm{x}, 0)=\log _{\mathrm{e}}\left(\frac{1}{2} \mathrm{x}^{2}+0.1\right)$

And either

Problem A-mixed boundary conditions $\mathrm{u}(1, \mathrm{t})+(0.6+\mathrm{t}) \frac{\partial \mathrm{u}(\mathrm{l}, \mathrm{t})}{\partial \mathrm{x}}=\log _{\mathrm{e}}(\mathrm{t}+0.6)+1$ $t \in(0,8]$

Or 
Problem B-Neumann boundary conditions

$\frac{\partial \mathrm{u}(1, \mathrm{t})}{\partial \mathrm{x}}=\frac{1}{(0.6+\mathrm{t})}, \mathrm{t} \in(0,8]$

The exact solution is $\mathrm{u}(\mathrm{x}, \mathrm{t})$

$\mathrm{u}(\mathrm{x}, \mathrm{t})=\log _{\mathrm{e}}\left(1 / 2 \mathrm{x}^{2}+\mathrm{t}+0.1\right)$

It was not practical to compute a numerical solution directly from Eq. (1.8) because the iterative procedure in Gear's method failed to converge. Hence to compare the relative accuracy of the two solution we used Eq. (2.7).

$\mathrm{z}^{( \pm 1)}$ as given in Eq. (2.11) (coefficients define $\mathrm{U}_{\mathrm{N}}(\mathrm{x}, \mathrm{t})$ )

and

$\mathrm{z}^{( \pm 1)}=0\left(\right.$ coefficients define $\left.\mathrm{U}_{\mathrm{N}}^{\mathrm{T}}(\mathrm{x}, \mathrm{t})\right)$

Graphs of error norms $\left\|\mathrm{U}_{\mathrm{N}}(\cdot, \mathrm{t})-\mathrm{u}(\cdot, \mathrm{t})\right\|_{\mathrm{x}} \quad$ and $\left\|\mathrm{U}_{\mathrm{N}}^{\mathrm{T}}(\cdot, \mathrm{t})-\mathrm{u}(\cdot, \mathrm{t})\right\|_{\mathrm{x}}$ against $\mathrm{t}$ for $\mathrm{N}=5,7$ and 9 and for problem $\mathrm{A}$ and $\mathrm{B}$ are given in table 1 . The numerical solution of Eq. (2.7) was computed using Gear's methods with a local error tolerance $0.5_{10}-8$. The improvement in accuracy obtained using the new algorithm can be seen for $\mathrm{N}>5$.

Problem C. To illustrate the numerical performance of the global element method we have considered the following problem taken from Bakker (1977):

$\frac{\partial \mathrm{u}}{\partial \mathrm{t}}=5 \mathrm{x}^{-2} \frac{\partial}{\partial \mathrm{x}}\left\{\mathrm{x}^{2} \frac{\partial \mathrm{u}}{\partial \mathrm{x}}\right\}-1000 \mathrm{e}^{\mathrm{u}}, \ldots$

$\mathrm{x} \in\left[0, \frac{1}{2}\right)$

$\mathrm{x}^{-2} \frac{\partial}{\partial \mathrm{x}}\left\{\mathrm{x}^{2} \frac{\partial \mathrm{u}}{\partial \mathrm{x}}\right\}-\mathrm{e}^{\mathrm{u}}, \mathrm{x} \in\left(\frac{1}{2}, 1\right]$

Subject to the boundary conditions

$\frac{\partial \mathrm{u}}{\partial \mathrm{x}}=0$, at $\mathrm{x}=0, \mathrm{u}(1, \mathrm{t})=1$, for $\mathrm{t}$

And initial condition $\mathrm{u}(\mathrm{x}, 0)=0$

We assume the internal boundary condition

$$
5 \lim \frac{\partial u}{\partial \underset{x \rightarrow \frac{1^{-}}{2}}{\partial x}}=\lim _{\substack{1^{+} \\ x \rightarrow \frac{1^{+}}{2}}} \frac{\partial u}{\partial x}
$$

There is a discontinuity between the boundary condition and the initial condition at $\mathrm{x}=1$.

We have compared the numerical solution obtained by the

a) Finite difference code given in Sincovec and Madson (1975).

b) Finite element code written by Bakker using linear basis functions.

In each case the time integration is performed using Gear's method with local error tolerance equal to $10^{-7}$ using mixed error test.

To measure the error we first compute the solution using a high precision run. The error can then be measured using the norm

$$
E(t)=\sqrt{\int_{0}^{1} x^{2}[U(x, t)-u(x, t)]^{2}} d x
$$

for $t \in(0,0.3]$

Where $U(x, t)$ is the computed solution at the point $(x, t)$ and the integral was evaluated using the trapezium rule with 100 points.

Figure 1 shows how $\mathrm{E}(\mathrm{t})$ varies with t. We have chosen 41 and 81 equally spaced mesh points for the finite difference and finite element codes. For the generalized Chebyshev method we have used two elements $[0,1 / 2]$ and [1/2,1] with $\mathrm{N}_{1}=\mathrm{N}_{2}=7$ (15mesh points) and four equally spaced elements with $\mathrm{N}_{\mathrm{j}}=9$ on each element (37 mesh point). We can see from the graphs given in Fig. 1 that very satisfactory results are obtained using the Chebyshec method. As we expect the discontinuity in the boundary and 
initial condition causes a large error initially which rapidly dies away.

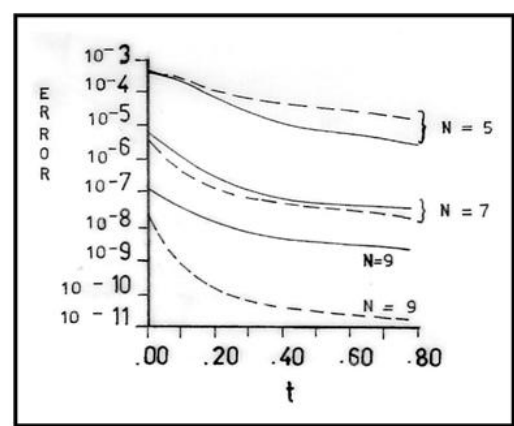

Problem-A-Mixed Boundary Conditions

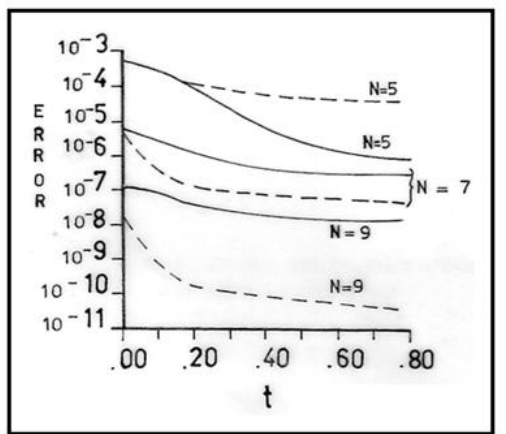

Problem-B-Neuman Boundary Conditions

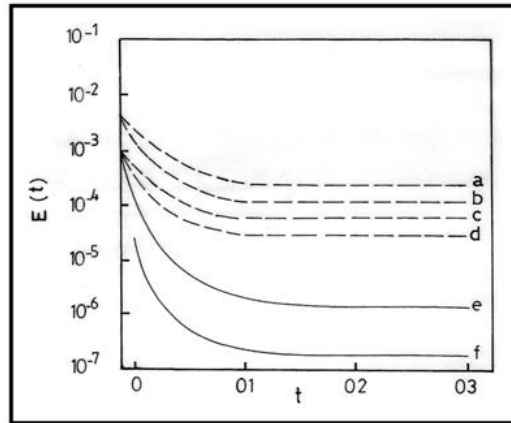

Fig (1): Graph of E(t) for the test problem (6.3) (a finite differences $(N=41)$; (b) finite elements $(N=41) ;(c)$ finite differences $(N=81)$; (d) finite elements $(N$ = 81): (e) chebyshev method $(N=15,2$ elements); (f) chebyshev method $(N=37$, 4 elements), $N$ denotes the number of mesh points (i.e, number of ODEs to solve).

The solid line_denotes the error $\| u_{N}(., t)$ $-u(., t)|| x$.
The dotted line .... Denotes the error $\left\|\mathrm{u}_{\mathrm{N}}^{\mathrm{T}}(., t)-u(., t)\right\| x$.

\section{Conclusion}

We have shown in this paper that the Chebyshev methods can be extended to handle general parabolic equations and that the generalized Chebyshev method [8-14], compares very favorably with the finite element (linear basis function) method and the finite difference method. An advantage of the Chebyshev approach is that it is easy to vary the size of an element and the degree of the polynomial used on each element. It remains an interesting problem to see if the perturbation term can be used to select the size of each element and the degree of the polynomial automatically in some optimum manner.

\section{References:}

1. Dew, P.M. 1978. A note on the numerical solution of quasi-linear parabolic p.d.e.s with error estimates, JIMA 21: 401-417.

2. Dew, P.M. and Walsh, J.W. 1981. A set of library routines for the numerical solution of parabolic equations in one space variable, A.C.M Trans. Math. Software 7: 295-314.

3. Basford, P.A. and Dew, P.M. 1980. An algorithm to compute the eigenvalues/ functions of the loplacian operator with a region containing a sharp corner, int. J. Comput. Math. 8.

4. Berzins, M. and Dew, P.M. 1980. A note on the extension of the Chebyshev method to quasi-linear parabolic p.d.e.s with mixed boundary conditions. int $\mathrm{J}$. Comput. Math, 8. issue 3: 249-263.

5. Fox, L. and Parker, I.B. 1968. Chebyshev polynomials in 
numerical analysis. Oxford University Press, Ed. 1., England, pp. 249.

6. Knibb, D. and Scraton, R. E. 1971. on the solution of parabolic partial differential equations in chebysher series. Comput J. 14, 1971: 428 432.

7. Sincovec, R.F. and Madsen, N.K. 1975. Software for non-linear partial differential equations, A.C.M. Trans Math. Software 1: 232-260

8. Miquel Grau-Sainchez and Jose M Gutie' rrez, 2003. Some variants of the Chebyshev-Halleg Family of methods with fifth order of convergence, int. J. Comput. Math, October.

9. Natasha Flyer and Paul N. Swarztrauber. 2002. The convergence of spectral and finite difference methods for initial Boundary value problem siam $\mathbf{J}$. sc1. Comput. 23(5): $1731-1751$.

10. Bouchard, B. and Touzi, N. 2004. Discrete approximation and Monte
- Carlo simulation of backward stochastic differential equations stoch. Process. Appl. 111: 175 206.

11. Bally, V., Pages, G. and printems, J. 2005. A quantization tree method for pricing and hedging multi dimensional American options. Math. Finance 15: 119 - 168.

12. Makarov, R. N. 2003. Numerical solution of quasilinear parabolic equations and backward stochastic differential equations. Russian J. Numer. Anal. Math. Modelling 18: $397-412$.

13. Delarue, F. 2004. Auxiliary SDEs for homogenizations of quailinear PDEs with periodic coefficients. Ann. Probab 32: 2305 - 2361 .

14. Pages, G., pham, H. and printems, J. 2004.optimal quatization methods and applications to numerical problems in finance in handbook on numerical method in finance ( $\mathrm{S}$. rachevged.):253-298.

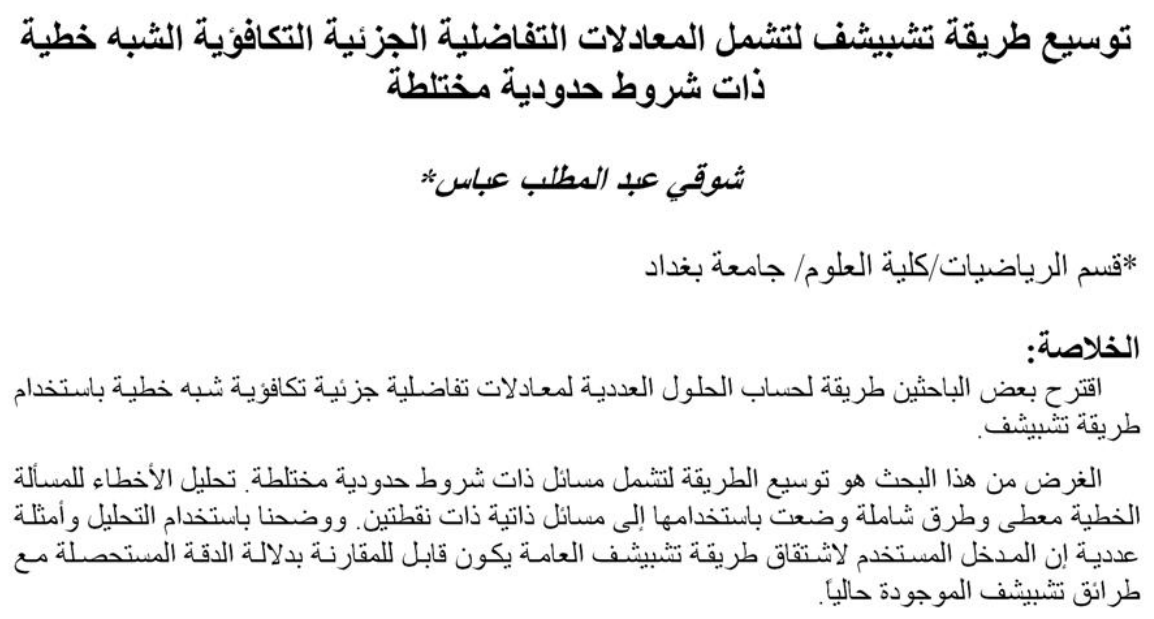

